Atmos. Chem. Phys., 8, 983-995, 2008

www.atmos-chem-phys.net/8/983/2008/

(C) Author(s) 2008. This work is licensed

under a Creative Commons License.

\title{
SAGE II measurements of stratospheric aerosol properties at non-volcanic levels
}

\author{
L. W. Thomason ${ }^{1}$, S. P. Burton ${ }^{2}$, B.-P. Luo ${ }^{3}$, and T. Peter ${ }^{3}$ \\ ${ }^{1}$ NASA Langley Research Center, Hampton, Virginia, USA \\ ${ }^{2}$ Science Systems and Applications, Inc., Hampton, Virginia, USA \\ ${ }^{3}$ Institute for Atmospheric and Climate Science, ETH Zurich, Zurich, Switzerland
}

Received: 22 February 2007 - Published in Atmos. Chem. Phys. Discuss.: 23 May 2007

Revised: 12 November 2007 - Accepted: 31 January 2008 - Published: 26 February 2008

\begin{abstract}
Since 2000, stratospheric aerosol levels have been relatively stable and at the lowest levels observed in the historical record. Given the challenges of making satellite measurements of aerosol properties at these levels, we have performed a study of the sensitivity of the product to the major components of the processing algorithm used in the production of SAGE II aerosol extinction measurements and the retrieval process that produces the operational surface area density (SAD) product. We find that the aerosol extinction measurements, particularly at $1020 \mathrm{~nm}$, remain robust and reliable at the observed aerosol levels. On the other hand, during background periods, the SAD operational product has an uncertainty of at least a factor of 2 due to the lack of sensitivity to particles with radii less than $100 \mathrm{~nm}$.
\end{abstract}

\section{Introduction}

SAGE II (Stratospheric Aerosol and Gas Experiment II) operated in low Earth orbit between October 1984 and August 2005 producing globally distributed profiles of ozone, $\mathrm{NO}_{2}$, water vapor, and aerosol extinction at four wavelengths from the middle troposphere though the stratosphere. It is the third in a series of four solar occultation instruments whose records begin in 1978 and end in March 2006. During this time the variability of aerosol in the stratosphere is dominated by a series of large volcanic perturbations and followed by multi-year recoveries. The most significant of these are the 1982 El Chichón eruptions, which continued

Correspondence to: $\mathrm{L} . \mathrm{W}$. Thomason

(l.w.thomason@larc.nasa.gov) to have observable effects into the SAGE II observational period, and the 1991 Pinatubo. The Pinatubo eruption was the most stratospherically significant volcanic event of the past 30 years and was responsible for significant radiative and chemical effects in the atmosphere (e.g., McCormick et al., 1995). The SAGE II data also records perturbations associated with a number of smaller volcanic events including the eruptions of Nevado del Ruiz and Nyamuragira (1985/1986), Kelut (1990), Cerro Hudson (1991), and Ruang and Reventador (2002). For most of the SAGE II record, the stratosphere can be considered to be in recovery from volcanic perturbations.

The 1979-2004 multi-instrument 1000-nm stratospheric optical depth is shown in Fig. 1. The stratospheric column optical depth was well in excess of 0.1 following the eruption of Pinatubo. However, in recent years, the lack of stratospherically significant volcanic activity has led to the lowest optical depth values in the 28 -year record with minimum values near 0.001 or a factor of more than 100 smaller than the maximum. At some altitudes, changes in the measured aerosol extinction have varied by a factor in excess of 1000 . Immediately following Pinatubo, the part of the aerosol extinction profiles accessible to SAGE II occultation often terminated well above the tropopause. Therefore, the optical depths between the eruption and mid 1993 are computed by extrapolating the profiles from the bottom of the profile down to the tropopause using lidar data as described in the SPARC Assessment of Stratospheric Aerosol Properties (Thomason and Peter, 2006). The premature termination of profiles is commonly referred to as the "saturation" effect that represents the upper bounds of the SAGE II dynamic range and occurs when the line of sight optical depth observed by the

Published by Copernicus Publications on behalf of the European Geosciences Union. 

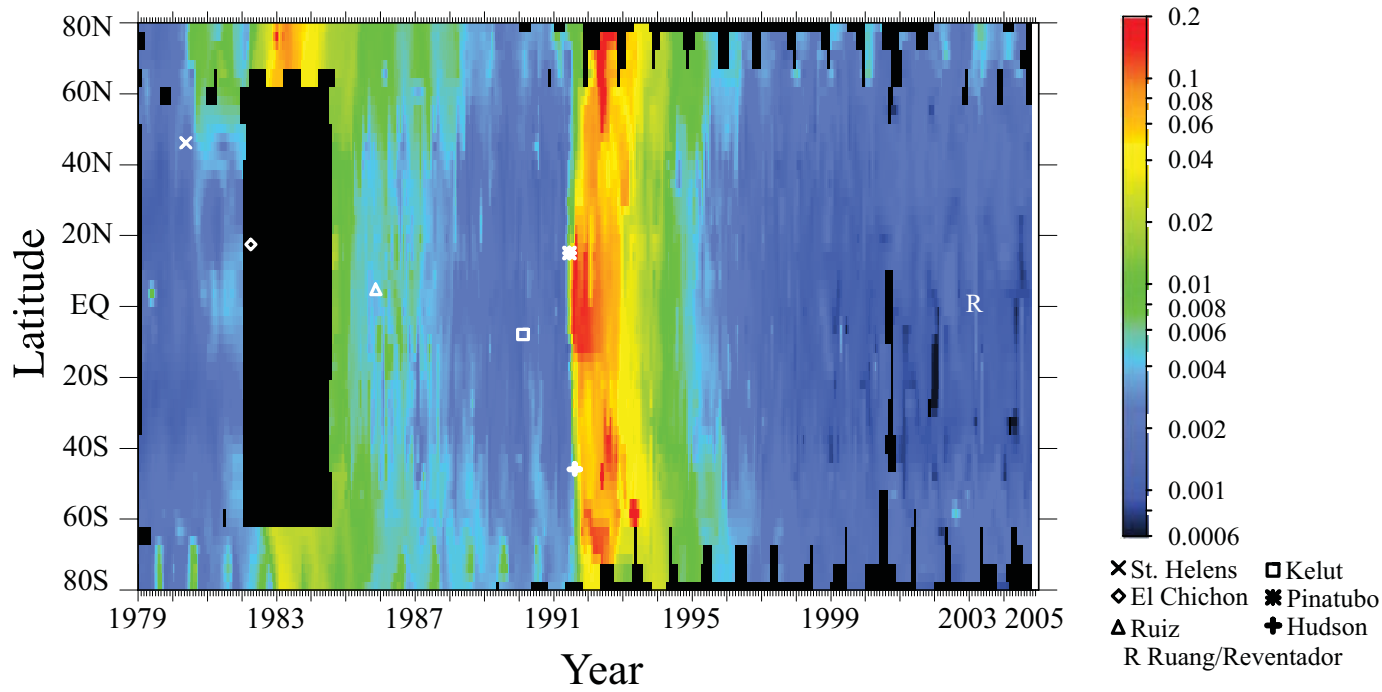

Fig. 1. The 1020-nm stratospheric optical depth from SAM II, SAGE, SAGE II and SAGE III for the period from January 1979 through the end of 2004. Between the June 1991 Pinatubo eruption and mid 1993, aerosol extinction coefficient profiles are supplemented by lidar data following the method described in Thomason and Peter (2006).

instrument (through the limb of the Earth's atmosphere) exceeds measurable bounds (a value of about 7). Saturation, due to Pinatubo effects, occurs from shortly after the eruption through mid-1993. It additionally occurs throughout the SAGE II record due to the presence of clouds, though mostly in the troposphere. In fact, clouds in the troposphere are the most common mechanism for defining the lower altitude extent of extinction profiles.

Since 2000, aerosol extinction has been characterized by relatively steady levels throughout the stratosphere. These levels may represent a volcanically unperturbed stratosphere. Except for a minor perturbation by the eruptions of Ruang and Reventador in late 2002, this is the only period of steady aerosol levels in the satellite measurement era dating back to the late 1970s. This extended period represents an opportunity to observe the optical manifestations of the processes that control stratospheric aerosol under volcanically quiescent conditions including possible human-derived effects. For this period, Fig. 2 shows the aerosol extinction in the tropics at altitudes between 18 and $30 \mathrm{~km}$. The SAGE II extinction record shows a significant annual cycle at $18 \mathrm{~km}$. Its source is not obvious as the data have been cleared of clouds (Kent et al., 1996; Thomason and Peter, 2006). Less than $20 \%$ of the observed cycle may be due to the annual temperature and water vapor cycle leading to a cycle in the water uptake of the $\mathrm{H}_{2} \mathrm{SO}_{4}-\mathrm{H}_{2} \mathrm{O}$ aerosol and hence its size, but more than $80 \%$ must be related to other effects such as seasonal differences in the amount of $\mathrm{H}_{2} \mathrm{SO}_{4}$ entering the stratosphere or seasonal differences in organic aerosol. There is also a significant aerosol variability that appears to have a period similar to the Quasi-Biennial Oscillation (QBO) at $30 \mathrm{~km}$, while there is virtually no evidence for these cycles at 22 or $26 \mathrm{~km}$.
With aerosol at such low levels, as a corollary to the saturation problem, it is sensible to ascertain the degree to which SAGE II extinction measurements remain dependable at the reported levels and, by extension, determine whether measurement features like the tropical annual aerosol extinction cycle are robust features of aerosol morphology. Several factors that are unimportant at high aerosol levels may influence the robustness of the measurements at low levels. These include dark current subtraction, altitude registration, and correction for the effects of molecular scattering and absorption by ozone and nitrogen dioxide. Herein, we discuss the sensitivity of the product to the major components of the processing algorithm used in the production of SAGE II aerosol extinction measurements. We focus on factors that have the potential for producing bias in the aerosol measurements, thus we neglect factors that are either too small (e.g., nitrogen dioxide clearing) or produce random noise (e.g., measurement noise). In addition to extinction, SAGE II provides an estimate of the aerosol surface area density (SAD) as an operational product (Thomason et al., 1997). Since visible and near-infrared wavelength aerosol extinction is insensitive to particles with radii smaller than $100 \mathrm{~nm}$, the robustness of SAD estimates based on these measurements is questionable. Therefore, we have also included a study of the limitations of SAD estimates based on SAGE II aerosol extinction measurements. 


\section{SAGE II aerosol extinction measurement sensitivity study}

\subsection{An overview of the retrieval process}

SAGE II is a solar occultation instrument. It records the attenuation of sunlight by the Earth's atmosphere at seven wavelengths between $386 \mathrm{~nm}$ and $1020 \mathrm{~nm}$ during each sunrise and sunset encountered by the spacecraft. As the sun rises or sets, the instrument scans across the face of the sun, thereby obtaining multiple measurements of total slant path transmittance for a given ray tangent altitude. Since measurements are also made for ray paths outside the atmosphere, this technique is self-calibrating. The tangent altitude of each ray path is calculated from spacecraft and sun ephemeris data, taking into account the shape of the Earth and atmospheric refraction. The total slant path optical depth data are corrected for molecular scattering using meteorological data from the National Centers for Environmental Prediction (NCEP) supplemented with climatological data at higher altitudes. Then the information for the seven SAGE II channels is separated into slant path optical depth contributions for ozone, nitrogen dioxide and water vapor plus aerosol in four channels (centered at $1020 \mathrm{~nm}, 525 \mathrm{~nm}$, $452 \mathrm{~nm}$ and $386 \mathrm{~nm}$ ) using a least squares technique in which aerosol effects at 448, 600, and $945 \mathrm{~nm}$ are estimated using a physically-based interpolation from the other channels. Finally, the slant path profiles undergo vertical inversion to produce vertical profiles of aerosol extinction in four channels, ozone and $\mathrm{NO}_{2}$ number density, and $\mathrm{H}_{2} \mathrm{O}$ mixing ratio (e.g., Chu et al., 1989). For the sensitivity study, we will show results based on occultations that occurred between $10^{\circ} \mathrm{N}$ and $30^{\circ} \mathrm{N}$ during the extended low aerosol loading period. This latitude band was chosen because column aerosol loading is relatively low in this region (see Fig. 1) and therefore it is potentially the most difficult region in which to make aerosol measurements; however, the following results are generally applicable to all latitudes.

\subsection{Sensitivity study}

The raw measurement obtained by the instrument is solar power as an integer number of counts from 3 or 4 (off-sun) to a few thousand, depending on the channel. The values measured through the Earth's limb are normalized by the exoatmospheric counts to generate transmittance measurements. The peak exoatmospheric count levels have generally decreased slowly over the lifetime of the instrument. Figure 3 shows the peak exoatmospheric count levels for the center of the Sun for the seven spectral channels from 1984 to 2005. Since the electronic noise level for the instrument is very low (less than one count), the signal-to-noise ratio for this data is very high. However, as the instrument scans from edge to edge across the face of the sun, the number of counts decreases toward zero, so only data from the center $90 \%$ of
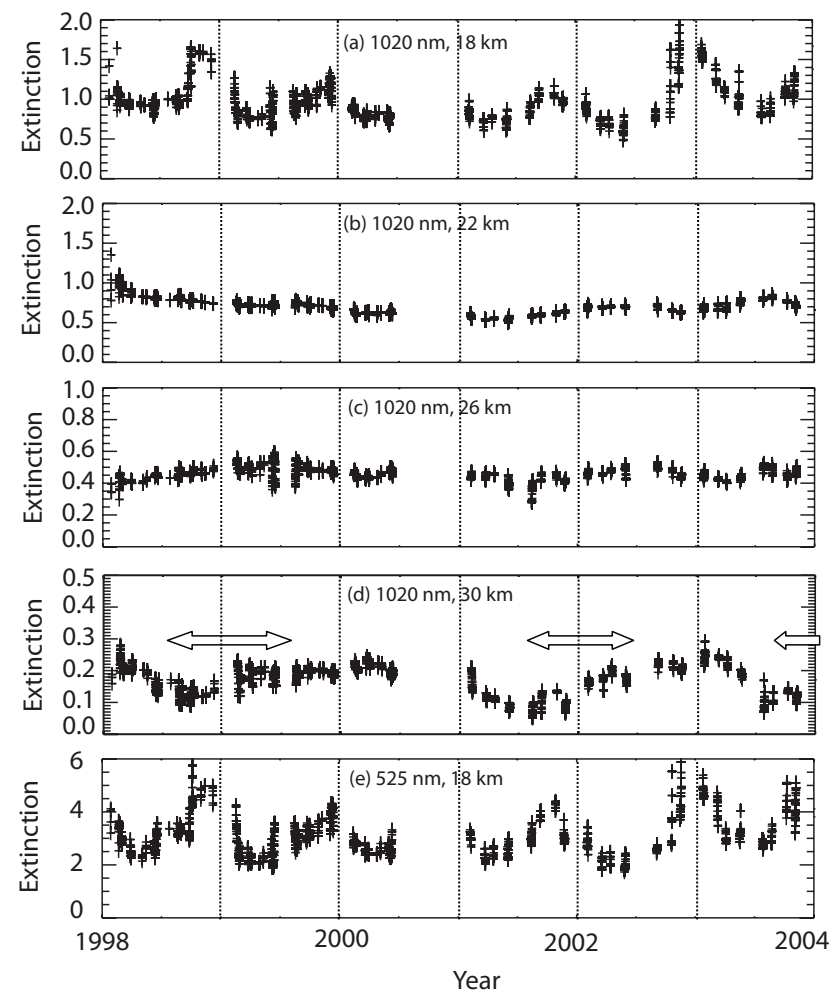

Fig. 2. SAGE II stratospheric 1020-nm aerosol extinction coefficient (in units of $\mathrm{km}^{-1}$ ) for altitudes of 18 (a), 22 (b), 26 (c) and 30 $\mathrm{km}$ (d) between $10^{\circ} \mathrm{N}$ and $10^{\circ} \mathrm{S}$ for the years 1998 through 2003. In addition, 525-nm aerosol extinction variability is shown in frame (e). The effects of the eruptions of Ruang and Reventador in late 2002 can be seen at $18 \mathrm{~km}$. Dashed vertical lines show 1 January of each year. Horizontal block arrows in (d) show easterly QBO as given by zonal winds at $50 \mathrm{mb}$ over Singapore.

the Sun is used to compute transmission. Count levels also decrease as the path through the atmosphere approaches the Earth's surface. Figure 4 shows the raw counts measured in the $1020 \mathrm{~nm}$ channel as a function of altitude for a typical event from December 2003 and demonstrates that the bulk of the on-sun measurements in the stratosphere and well into the troposphere have count levels of 1500 or higher. Therefore, the transmittance accuracy is on the order of $0.1 \%$.

The transmittance signal in each channel is attributable to multiple sources: aerosol and molecular scattering and absorption by ozone, $\mathrm{NO}_{2}$, and water vapor. Specifically, the aerosol extinction signal in the $1020 \mathrm{~nm}$ channel must be separated from the signal due to molecular scattering plus a small contribution from ozone absorption. Figure 5 shows the fraction of the signal in the $1020 \mathrm{~nm}$ channel due to aerosol. This fraction varies from about $40 \%$ to $60 \%$ below $30 \mathrm{~km}$ showing that at these altitudes $1020-\mathrm{nm}$ extinction is not sensitive to the removal of interfering species. Above $30 \mathrm{~km}$, the aerosol fraction decreases rapidly and the importance of the molecular correction increases rapidly. 


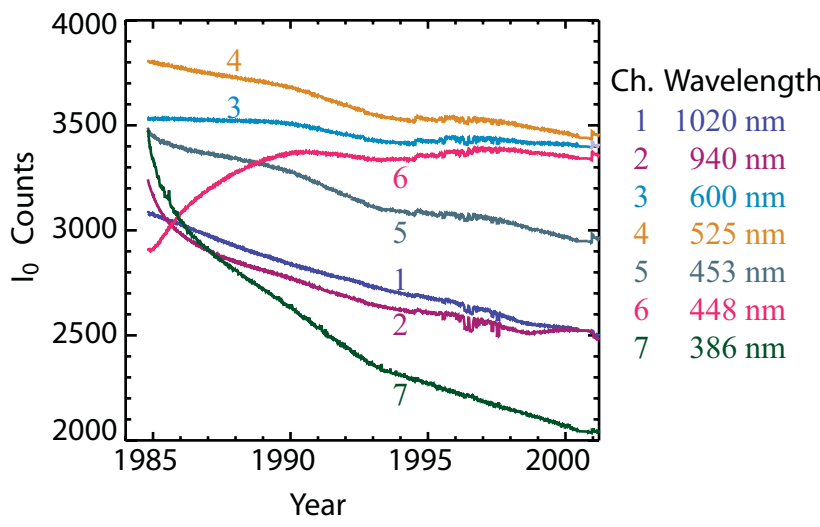

Fig. 3. SAGE II exoatmospheric counts for channels 1 through 7 through the lifetime of the instrument. The channels have central wavelengths of $1020,940,600,525,453,448$, and $386 \mathrm{~nm}$, respectively. The lines are labeled with channel number followed by central wavelength.

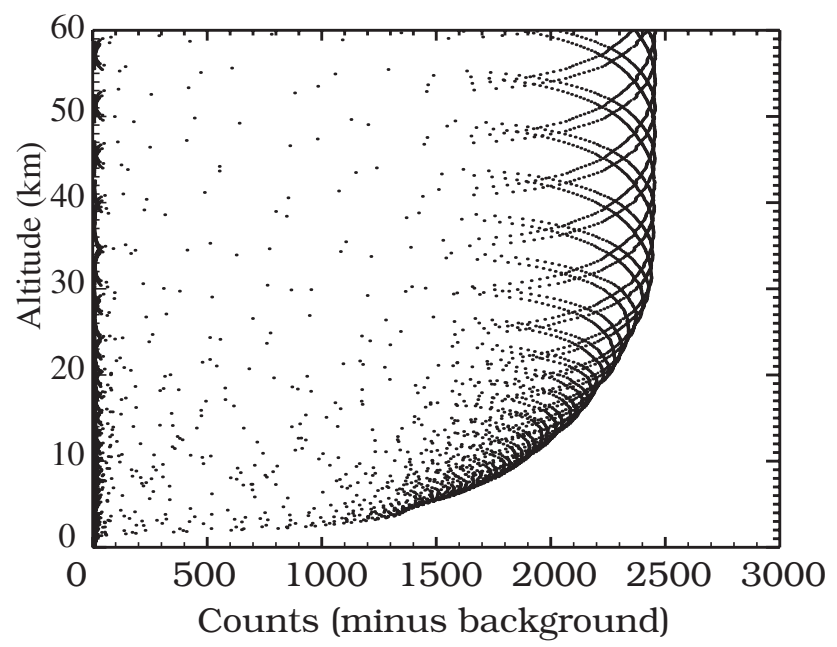

Fig. 4. Instrument counts, minus background, for the center $90 \%$ of the sun, as a function of altitude, for an event which occurred on 19 December 2003 at $21.1^{\circ} \mathrm{N}, 142.0^{\circ} \mathrm{E}$.

Other parameters besides the sensitivity to aerosol could potentially handicap the aerosol measurements, including a number of possible sources of bias hinted at in the description of the retrieval above. The aim of the sensitivity study is to examine the effect on $1020 \mathrm{~nm}$ and $525-\mathrm{nm}$ aerosol extinction data of various sources of systematic error, including the dark (off-sun) measurement, the altitude registration, the meteorological input data, and the gas cross-sections. These factors are not significant at high and moderate aerosol levels but may be significant at the low levels observed after 2000 . In the following discussion, we demonstrate that the 1020$\mathrm{nm}$ aerosol extinction is not sensitive to any of these sources while the $525-\mathrm{nm}$ aerosol extinction is sensitive only to the ozone cross-section.

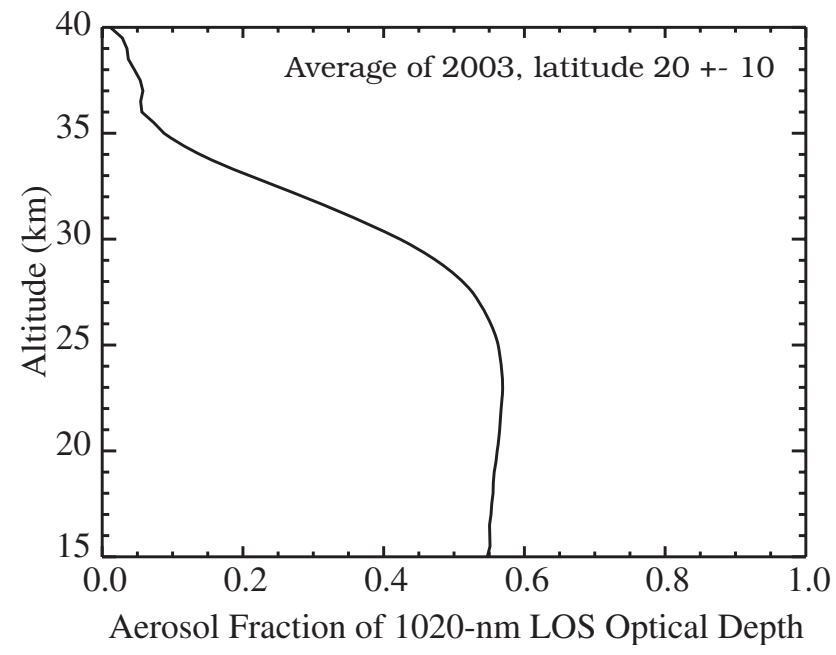

Fig. 5. Fraction of the measured slant path optical depth in the 1020$\mathrm{nm}$ channel that is attributed to aerosol. All events between $10^{\circ} \mathrm{N}$ and $30^{\circ} \mathrm{N}$ in 2003 are included in the average shown here. Under the conditions of interest the $\mathrm{H}_{2} \mathrm{SO}_{4}-\mathrm{H}_{2} \mathrm{O}$ aerosol is expected to fully evaporate at temperatures above $\sim 238 \mathrm{~K}$, corresponding to altitudes between $35 \mathrm{~km}$ and $40 \mathrm{~km}$.
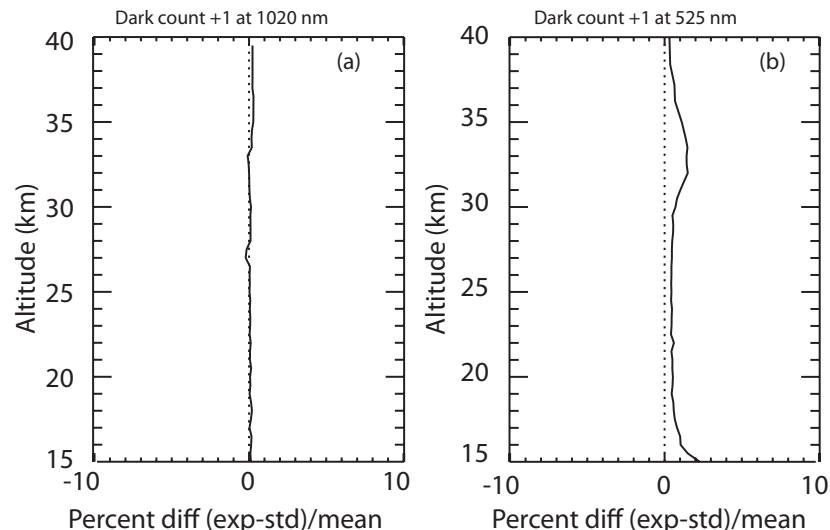

Fig. 6. Effect on the ratio of $525 \mathrm{~nm}$ to $1020 \mathrm{~nm}$ aerosol extinction of increasing the number of counts subtracted from the signal to correct for dark current. The plot shows the percent difference of the means of multiple processed events, with the sense $(\exp -\mathrm{std}) /$ mean $\times 100 \%$ where exp and std refer to the perturbed subtraction and the assumed-correct subtraction, respectively, and the mean is $(\operatorname{std}+\exp ) / 2$. The occultation events included are those between $10^{\circ} \mathrm{N}$ and $30^{\circ} \mathrm{N}$ latitude in the year from October 2001 to September 2002. Panel (a): experimental perturbation applied to the $1020 \mathrm{~nm}$ channel. Panel (b): the same for the $525 \mathrm{~nm}$ channel.

\subsubsection{Dark count subtraction}

The dark count value is measured by pointing the instrument away from the sun. It represents the instrument's "zero" level. In processing, this value is subtracted from the raw solar power measurements before the calibration by the 
exoatmospheric scans. The dark count values for all seven channels are between 3 and 4 counts, or about one or two one-thousandths of the maximum intensity measured. Over the lifetime of the instrument, dark count values have been stable for each measurement channel. Ironically, the generally desirable characteristics of very small measurement noise and a high stability of the dark count level conspire to make precise measurements of dark counts difficult. The uncertainty is about one half count and therefore is a large fraction of the overall dark count value.

In practice, dark count subtraction will have its greatest impact when the channels are near saturation and the measured total count level is close to the dark count value. In the stratosphere, this only occurs immediately after the Pinatubo eruption in 1991. In stratospheric background periods it occurs only in the presence of clouds for the 1020-nm channel and for clouds or in clear skies at and below about $6 \mathrm{~km}$ for the 525-nm channel. In order to determine the sensitivity of the aerosol measurements to the uncertainty in the dark count subtraction, we performed two experiments in which the magnitude of the dark count subtraction was changed by one count, first in the $1020 \mathrm{~nm}$ channel and then in the 525 $\mathrm{nm}$ channel. Figure 6 shows the results of these experiments on the ratio of detected aerosol extinction $(525 \mathrm{~nm} / 1020 \mathrm{~nm})$ for all profiles in the $10^{\circ}-30^{\circ} \mathrm{N}$ latitude band in October 2001 through September 2002. They were reprocessed with a change in the dark count subtraction of one count. The resulting systematic change when the assumed background is changed in the 1020-nm channel is a fraction of a percent. The effect of adjusting the 525-nm background is slightly larger, but is still less than a percent below $30 \mathrm{~km}$, except in the vicinity of $15 \mathrm{~km}$ where it is about $2 \%$ in the $525-\mathrm{nm}$ extinction (visible here as a similar change in the ratio, since the change in 1020-nm extinction is near zero). As expected, we find that background stratospheric aerosol measurements are not greatly influenced by the dark count subtraction.

\subsubsection{Altitude registration sensitivity}

The determination of the ray tangent altitude is another potential source of systematic error. In a similar experiment to that described above, the altitude registrations were artificially shifted upward and downward by $100 \mathrm{~m}$. This shift is comparable to the altitude registration uncertainty (100 to $200 \mathrm{~m}$ ) derived from ozone intercomparisons [Borchi and Pommereau, 2007]. The shift was experimentally applied to all profiles in the $10^{\circ}-30^{\circ} \mathrm{N}$ latitude band in October 2001 through September 2002. The result, shown in Fig. 7 shows that the effect on $1020 \mathrm{~nm}$ aerosol extinction is less than 3\% throughout the stratosphere. The effect of an upward (downward) shift on the $525-\mathrm{nm}$ aerosol measurement is to decrease (increase) the inferred extinction by about $2-5 \%$ almost everywhere in the stratosphere, with the peak shift near $31-33 \mathrm{~km}$. Even at the peak value, where the difference is $6 \%$ in the measured 525-nm aerosol extinction and in the 525 to
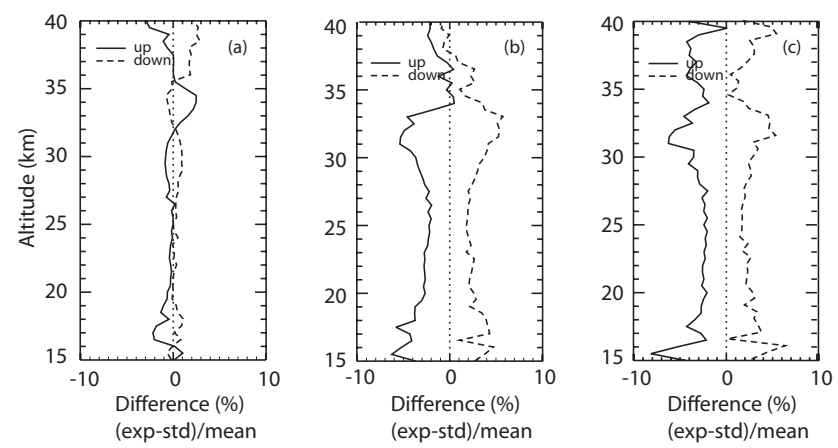

Fig. 7. Effect of a shift in the altitude registration upward (solid lines) or downward (dashed): difference in percent between shifted and unshifted aerosol extinctions are shown for 1020-nm aerosol extinction (a), 525-nm aerosol extinction (b) and the ratio of 525$\mathrm{nm} / 1020-\mathrm{nm}$ extinction (c). The sense of the percent difference is (experimental-standard)/mean where experimental is the mean of all the perturbed measurements, standard is the mean of unperturbed measurements and mean is (experimental+standard)/2. The occultation events included are those between $10^{\circ} \mathrm{N}$ and $30^{\circ} \mathrm{N}$ for the year from October 2001 to September 2002 removing measurements that appear to have been contaminated by clouds.

1020-nm extinction ratio, the systematic error resulting from this experiment is quite small.

\subsubsection{Temperature profile sensitivity}

In our third experiment, we examine the effect on the SAGE II aerosol extinction measurements of an artificially induced systematic bias in the NCEP temperature profiles at the 100mb level. Randel et al. (2004) has reported that the NCEP tropopause temperature is too warm by approximately $2-3 \mathrm{~K}$ with the potential for larger errors at $10 \mathrm{mb}$. The possibility of a systematic error or a spurious trend in the temperature data is of particular concern to SAGE II measurements since such an error can produce a bias or an artificial trend in the aerosol measurements. Accordingly, we have experimentally adjusted the temperature profiles that are input to the SAGE II retrieval for the same $10^{\circ}-30^{\circ} \mathrm{N}$ latitude band in October 2001 through September 2002.

SAGE II receives NCEP temperatures at 18 pressure levels $(1000,850,700,500,400,300,250,200,150,100,70,50$, $30,10,5,2,1$, and $0.4 \mathrm{mb}$ ) and interpolates this data to a $0.5-$ $\mathrm{km}$ profile of temperature and pressure. For this experiment, we adjusted the temperature at one of the pressure levels and the perturbation is spread at altitudes between the pressure levels immediately above and below the perturbed level. The primary test was to adjust the temperature at the $100 \mathrm{mb}$ level by $+3 \mathrm{~K}$. The result is an increase of $9 \%$ in a narrow region near $16 \mathrm{~km}$ and a decrease of generally less than $1 \%$ in the 525-nm channel in the stratosphere (Fig. 8, top middle). In the 1020-nm channel, the narrow peak is somewhat smaller, while stratospheric values again change by $1 \%$ or less (Fig. 8 , 

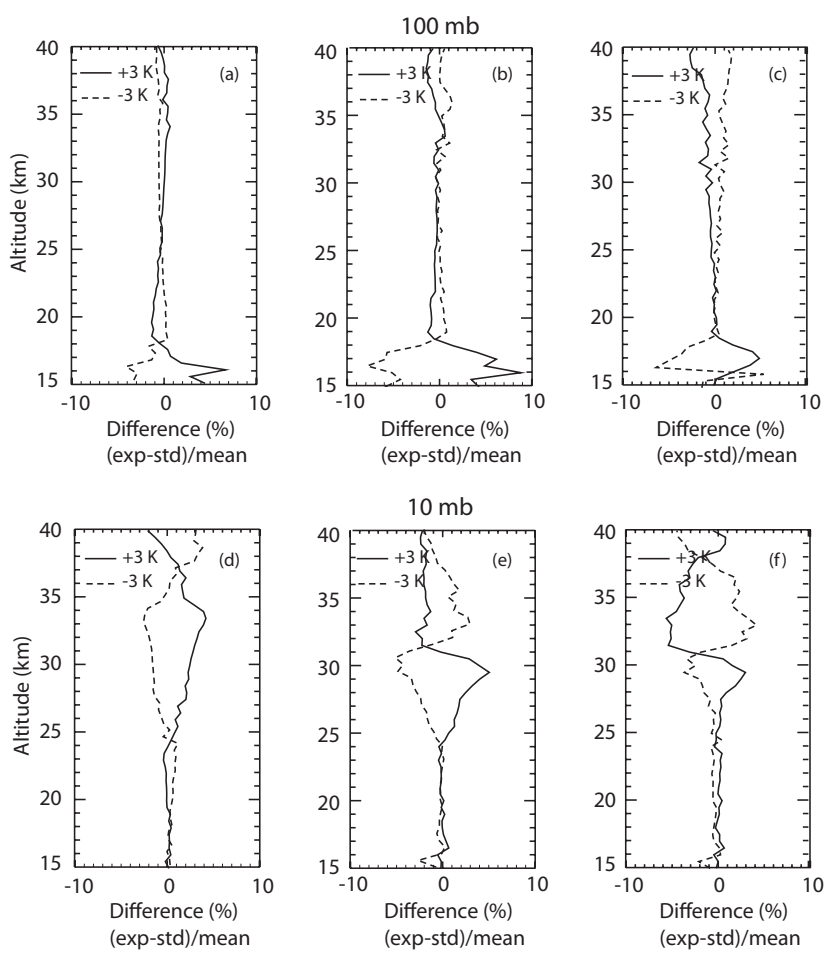

Fig. 8. Panels (a), (b), and (c) show the result of perturbing the input temperature value at $100 \mathrm{mb}$ by $3 \mathrm{~K}$ (solid lines) and $-3 \mathrm{~K}$ (dashed). Percent differences for the 1020-nm extinction (a), 525-nm extinction (b) and 525-nm/1020-nm ratio (c) are (experimental-standard)/mean with the meanings as in Fig. 6. Same suite of measurements and cloud clearing is also the same as in Fig. 6. Panels (d), (e), and (f): same at the $10 \mathrm{mb}$ level.

top left). Conversely, decreasing the temperature results in equivalent changes opposite in sign to those described above (Fig. 8, top left, middle, and right).

Temperature uncertainties at a higher altitude may have a stronger relative impact on stratospheric aerosol measurements. Therefore, in a separate experiment, we have tested the response of the aerosol measurements to an increase or decrease of $3 \mathrm{~K}$ at the $10 \mathrm{mb}$ level (about $31 \mathrm{~km}$ ). The bottom panels of Fig. 8 demonstrate the response of the aerosol extinction measurements to this perturbation. Increasing the temperature produces an increase in the measured 1020-nm aerosol extinction between 25 and $38 \mathrm{~km}$, with a peak effect of about $4 \%$ near $34 \mathrm{~km}$. The effect on the $525-\mathrm{nm}$ measurement is increasing between about 25 and $31 \mathrm{~km}$, with a peak of about $5 \%$ at $29.5 \mathrm{~km}$, and a constant decrease of about $2 \%$ above $31 \mathrm{~km}$. In summary, a $1 \%$ error in absolute temperature translates into an error of up to $4 \%$ in the 525 and $1020 \mathrm{~nm}$ extinction coefficients and similarly in their ratio.

\subsubsection{Sensitivity to mirror correction}

In an additional experiment, we assess the effect of an imposed bias in the mirror correction. The mirror correction is a small adjustment, nearly linear with altitude that is made to correct for variation in the mirror reflectivity as a function of the mirror angle. The correction is small throughout the depth of the atmosphere and never exceeds $1 \%$ with an estimated relative uncertainty of $0.4 \%$. For testing, we made the mirror correction one sigma $(0.4 \%)$ larger than the operational values. The effect on the $525-\mathrm{nm}$ and $1020-\mathrm{nm}$ aerosol extinction profiles is negligible throughout the $15-35 \mathrm{~km}$ region, with a maximum effect of only $1.8 \%$ near $38 \mathrm{~km}$ in the $1020-\mathrm{nm}$ channel and less than $1 \%$ at $34 \mathrm{~km}$ in the $525-\mathrm{nm}$ channel. These effects are very small and only occur at the high altitude extreme of the aerosol profiles where measurement uncertainty is already close to $100 \%$.

\subsubsection{Sensitivity to aerosol model}

The SAGE II species retrieval includes an aerosol model which is used to calculate the aerosol extinction in the 600$\mathrm{nm}$ channel where it is an interfering species in the ozone retrieval. The calculation estimates the aerosol slant path optical depth as a linear combination of the aerosol optical depth in the 1020-nm and 525-nm channels. The model, similar to that described by Chu et al. (1989), uses a set of linear coefficients to relate extinction at 525 and $1020-\mathrm{nm}$ to that at $600 \mathrm{~nm}$ based upon a family of log-normal aerosol size distributions that are representative of stratospheric aerosol. The model produces 600 -nm aerosol extinction estimates with an estimated accuracy of $\sim 1 \%$. For the sensitivity study, we perturbed the $600-\mathrm{nm}$ aerosol by changing the coefficients multiplying the other two channels, both separately and together, by one percent. Since the retrieval is a simultaneous retrieval of the gaseous species and aerosol in all channels, there is potential crosstalk between the retrieval of ozone and aerosol extinction, particularly for the shorter wavelength aerosol channels, through the aerosol model. However, we find that these perturbations have a negligible effect on the 1020-nm and 525-nm aerosol extinction. The effect on the 1020 -nm aerosol extinction was effectively zero (less than $0.01 \%$ ) in all three tests; the maximum effect on the $525-\mathrm{nm}$ aerosol extinction was less than four tenths of a percent (this occurred when both coefficients were simultaneously biased away from their standard values in the same direction).

\subsubsection{Ozone cross-section sensitivity}

The final component of the sensitivity study is an assessment of the effect of a systematic error in the ozone cross-section. SAGE II version 6.2 uses the ozone cross sections of Anderson and Mauersberger (1992) and Anderson et al. (1990, 1991, 1993a, 1993b) and the temperature dependence measured by Burkholder and Talukdar (1994), as compiled by Shettle and Anderson (1994). These sources report uncertainties of $1-2 \%$ near the peak of the Chappuis band and near $525 \mathrm{~nm}$. Ozone absorption cross-sections for each channel are required for the retrieval of individual species. These 
are derived by combining the above cross sections with the SAGE II instrument's filter response function. Since the 525$\mathrm{nm}$ channel is within the Chappuis band, the cross section at that channel is a potential source of systematic error in the aerosol measurements. On the other hand, the ozone cross section at $1020 \mathrm{~nm}$ is very small and unlikely to play a role in the aerosol extinction coefficient measurement quality. The test consists of a perturbation of $1 \%$ in the ozone cross section for the 525-nm channel. As expected, Fig. 9 shows that there is almost no effect on the $1020 \mathrm{~nm}$ aerosol extinction, but a significant effect on $525 \mathrm{~nm}$ aerosol extinction that increases with altitude reaching $18 \%$ at $31 \mathrm{~km}$. A related experiment was performed in which the cross section for the primary ozone channel (at $600 \mathrm{~nm}$ ) was changed by $1 \%$. The effect on the 525-nm aerosol extinction measurement is in the opposite sense than the previous experiment but with a similar altitude dependence. The peak change is about $20 \%$ near $33 \mathrm{~km}$. The effect on the $1020 \mathrm{~nm}$ aerosol extinction measurement is again nearly zero.

As a result, we find that a systematic bias in the ozone cross section (either in an absolute sense or in its temperature dependence) could potentially produce artificial seasonal cycles or other effects in the inferred aerosol extinction coefficient variability but only at the short wavelength channels like $525 \mathrm{~nm}$. The 1020-nm channel is essentially independent of ozone cross section errors and therefore, annual cycles in aerosol that appear in both the short wavelength and the 1020-nm channels are likely to reflect real changes in the aerosol morphology rather than a residual ozone signature. This includes the annual cycles (shown Fig. 2) in the tropical lower stratosphere (amplitude $\sim 20 \%$ ) and the annual cycle near $30 \mathrm{~km}$ where the amplitude is near $50 \%$. It also implies that the real uncertainty in the $525-\mathrm{nm}$ ozone cross section must be significantly less than $1 \%$.

\subsection{Summary of aerosol extinction coefficient sensitivity study}

We find that during the low stratospheric aerosol levels found beginning in 2000 and continuing through the end of its mission in 2005, SAGE II aerosol extinction coefficient profiles remained robust and reliable. While the relative uncertainties associated with measurement noise were larger than during higher aerosol loading periods, the potential for significant measurement bias remained low. For these conditions and the factors as tested, the largest departure at $1020 \mathrm{~nm}$ is less than $5 \%$ from the tropopause to $30 \mathrm{~km}$ and is dominated by the a priori temperature profile data used in the data processing. At $525 \mathrm{~nm}$, the largest departures were less than $10 \%$ through most of the lower stratosphere and approaches $20 \%$ at $30 \mathrm{~km}$. At this wavelength, the bias potential is dominated by uncertainty in the temperature profile data and in the ozone cross section. At background aerosol levels and given the full range of potential error in the retrieval parameters, it
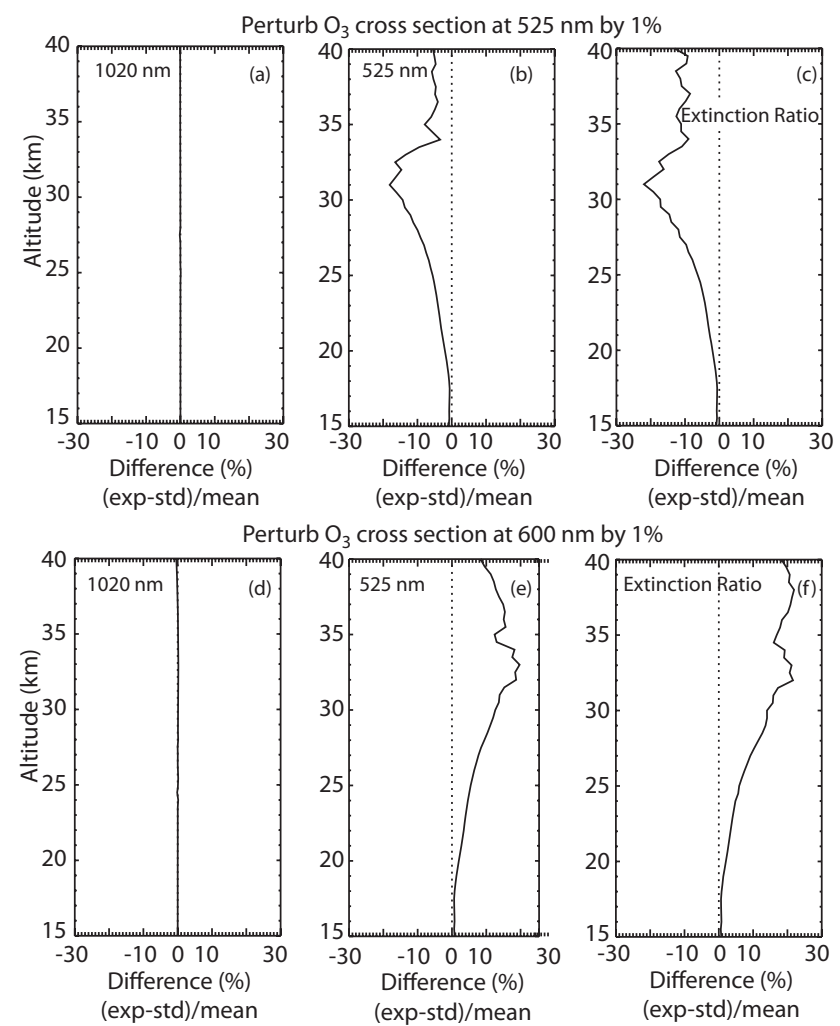

Fig. 9. This figure shows the effect of perturbing the ozone cross section at $525 \mathrm{~nm}$ (panels (a), (b), and (c)) and separately at $600 \mathrm{~nm}$ (panels (d), (e), and (f)) by 1\%. The effects on the 1020-nm aerosol extinction measurement ((a) and (d)), 525-nm aerosol extinction measurement ((b) and (e)) and the ratio ((c) and (f)) are shown. Details of the experiments are otherwise the same as Figs. 6, 7, 8, and 9 . Note the range of the abscissa has been increased on these plots compared to previous figures.

is difficult to produce a bias exceeding $10 \%$ at $1020 \mathrm{~nm}$ and $20 \%$ at $525 \mathrm{~nm}$ (below $25 \mathrm{~km}$ ).

\section{Surface Area Density Estimation Sensitivity}

\subsection{A model for determining the limiting bounds on SAD}

The operational SAGE II data processing includes estimated surface area density (SAD) beginning with the release of Version 6.2. The method follows that described by Thomason et al. (1997) except the coefficients used in the operational retrieval are weighted by measurement uncertainty thereby moving the SAD derivation dependence toward the 525 and 1020-nm channels rather than the short wavelength channels that are generally less reliable. Operationally, this approach was simplified to this expression

$$
\mathrm{SAD}=k_{1020}\left(\frac{1854.97+90.137 r+66.97 r^{2}}{1 .-0.1745 r+0.00858 r^{2}}\right)
$$



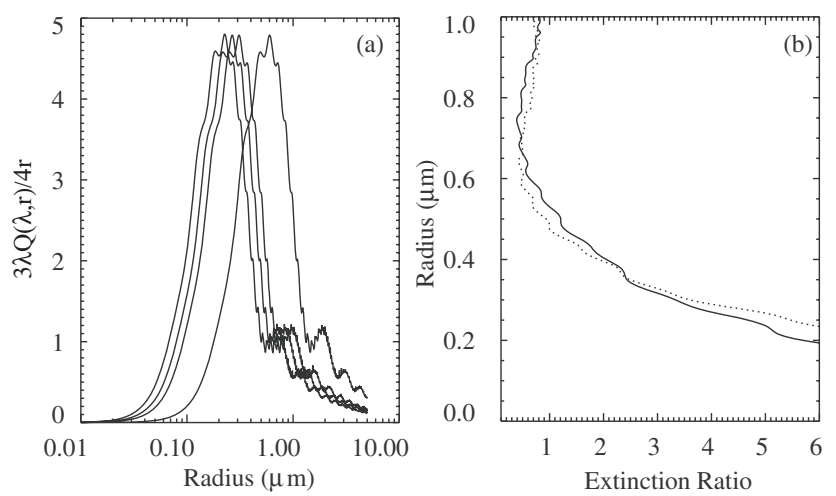

Fig. 10. (a) Extinction kernels for SAGE II aerosol extinction channels at 385 (left-most), 452, 525, and $1020 \mathrm{~nm}$ (right-most) for spherical water/sulfuric acid drops at stratospheric temperatures. (b) The solid line shows the particle radius as a function of the 525$\mathrm{nm}$ to the 1020-nm extinction kernel ratio (or extinction coefficient ratio for a monodispersed aerosol). The dotted line shows the particle radius as a function of the 452-nm to the 1020-nm extinction kernel ratio.

where $r$ is the 525 to $1020-\mathrm{nm}$ aerosol extinction ratio, and $k_{1020}$ is the $1020-\mathrm{nm}$ aerosol extinction coefficient in units of $\mathrm{km}^{-1}$ and the equation yields surface area density in units of $\mu \mathrm{m}^{2} \mathrm{~cm}^{-3}$. This technique was shown to produce values comparable with those produced by in situ instruments such as the University of Wyoming Optical Particle Counter (OPC) during the post-Pinatubo period (e.g., Thomason et al., 1997) but more recent work shows that it tends to underestimate OPC-derived SAD during low aerosol loading periods such as the current period (e.g., Thomason and Peter, 2006). It is not surprising that SAD calculations based on visible wavelength extinction measurements are less robust during low aerosol periods. This occurs in these periods because the bulk aerosol properties like SAD become heavily dependent on particles smaller than $100 \mathrm{~nm}$ which are rather poor scatterers and thus have only a small impact on measured extinction values. Figure 10a shows the aerosol extinction kernels for the four SAGE II measurement wavelengths (386, 452, 525, and $1020 \mathrm{~nm}$ ) assuming spherical particles composed of a mixture of sulfuric acid and water. Generally, aerosol extinction coefficient and particle size are positively correlated; that is, as aerosol extinction coefficient increases the mean particle size also increases. Thus, for low aerosol loading it is possible that a significant fraction of SAD lies at particle sizes to which visible wavelength aerosol extinction is almost totally insensitive and, as a result, the calculation of SAD is prone to substantial uncertainties. The retrieval of SAD for low aerosol loading is not necessarily biased to low values but rather it is highly dependent on how the retrieval process fills the small end of the particle size distribution and thus can be biased either high or low. This will be demonstrated later in this section. Many techniques have been applied to this calculation for SAGE II data, each of which filled this "blind spot" in a somewhat different manner (Wang et al., 1989; Thomason et al., 1997; Steele et al., 1997; Yue et al., 1999; Bingen et al., 2004). The operational SAD retrieval puts relatively little material at radii smaller than $50 \mathrm{~nm}$ and thus is likely to produce SAD values that are biased low to some degree (Thomason et al., 1997).

SAD is an important parameter in stratospheric chemistry as well as for light scattering and absorption, and hence for stratospheric heating and consequently dynamics. The background aerosol levels currently observed establish a baseline for SAD effects. As a result, it is important to establish the level of reliability for SAGE II SAD estimates for use in chemical and radiative modeling. This is particularly important since SAGE II provides a unique global view of the aerosol burden from 1984 into 2005 spanning the entire Pinatubo period. The only other comparable data set is that provided by the Halogen Occultation Experiment (HALOE) which is also a space-based solar occultation experiment that operates in the infrared. HALOE produces SAD estimates that are in fact smaller than those estimated from SAGE II during background periods (Hervig et al., 1998, 2002). To quantify the range of possible solutions for SAD during background periods, we will in the following develop simple models that allow us to put bounds on the maximum and minimum values for SAD that are consistent with the measured aerosol extinction and its wavelength dependence. These models provide rigorous limits on the SAD calculation but are not meant to produce a new SAD retrieval algorithm.

\section{Method 1}

For the first approach, the minimum SAD value consistent with observed aerosol extinction is a straightforward calculation. It is based on the observation from Figure 10a that the Mie scattering efficiency monotonically increases for particle sizes between 0 and $\sim 0.5 \mu \mathrm{m}$. As a result, on a per particle basis, the largest particles produce the most extinction at the cost of the smallest SAD. Thus the minimum possible SAD occurs for a monodispersed aerosol at the radius that preserves the observed extinction wavelength dependence modified by measurement uncertainty. For this model, aerosol extinction is given by

$k(\lambda)-\varepsilon(\lambda)=N_{\min } Q\left(r_{\min }, \lambda\right) \pi r_{\min }^{2}$,

where $k$ and $\varepsilon$ are the aerosol extinction coefficient and its associated uncertainty at wavelength $\lambda, \mathrm{N}_{\min }$ and $r_{\min }$ are the number density and radius of the monodispersed aerosol, and $Q(r, \lambda)$ is the Mie extinction efficiency seen in Fig. 10a. Figure $10 \mathrm{~b}$ shows the 525 to 1020 -nm extinction ratio to particle radius relationship for this model. This relationship is robust for particle sizes from 0 to $0.5 \mu \mathrm{m}$ but becomes multivalued at larger radii where the extinction ratio approaches 1. As a result, this method becomes ill-behaved for high 
aerosol loading periods (e.g., post-Pinatubo) and other situations where the measured extinction ratio is small. The minimum $\mathrm{SAD}, \mathrm{SAD}_{\min }$, is computed by using the 525 to 1020 $\mathrm{nm}$ extinction ratio, $(k(525 \mathrm{~nm})-\varepsilon(525 \mathrm{~nm})) / k(1020 \mathrm{~nm})$, to infer $r_{\min }$ then $N_{\min }$ is computed using Eq. (2) above. Finally, $\mathrm{SAD}_{\min }$ is given by $4 \pi N_{\min } r_{\min }^{2}$.

From a mathematical perspective, the maximum possible SAD that can be produced from SAGE II measurements is unbounded. Since particles smaller than $0.1 \mu \mathrm{m}$ are poor scatterers, it is possible to produce virtually unlimitedly large values of SAD by adding to the aerosol distribution derived for the minimum SAD (preserving the measured extinction coefficients) a second monodispersed mode at a very small radius $(<<0.1 \mu \mathrm{m})$. For instance, using enough $10 \mathrm{~nm}$ particles to perturb the 525 -nm aerosol extinction by the measurement uncertainty $(\sim 10 \%)$ produces SAD values in excess of $10^{4} \mu \mathrm{m}^{2} \mathrm{~cm}^{-3}$ at the cost of a particle density on the order of $10^{7} \mathrm{~cm}^{-3}$ for conditions where the operational method produces values on the order of $1 \mu \mathrm{m}^{2} \mathrm{~cm}^{-3}$. Clearly, number densities of this order are physically unrealistic but this illustrates the scope of the mathematical freedom afforded in SAD calculations by visible near infrared wavelength extinction measurements.

An alternative approach to estimating a maximum value of SAD is based on the observation from in situ measurements that aerosol number density (for radii greater than about $10 \mathrm{~nm}$ ) tends to be around $10 \mathrm{~cm}^{-3}$ independent of the details of the size distribution (Deshler et al., 2003). The physical reason for this is coagulation, which takes typically one year to reduce $10 \mathrm{~cm}^{-3}$ to half of this value, whereas it takes approximately one month to halve $100 \mathrm{~cm}^{-3}$ and 3 days to halve $1000 \mathrm{~cm}^{-3}$. In light of this, we compute a second monodispersed mode that brings the total number density to a fixed value, $N_{\text {total }}=20 \mathrm{~cm}^{-3}$, at a radius that perturbs the shortest wavelength aerosol extinction wavelength used in the calculation by the measurement uncertainty $\varepsilon(\lambda)$. Since increasing the total number density monotonically increases the inferred SAD, we choose $20 \mathrm{~cm}^{-3}$ since it should exceed the number density in most circumstances in the stratosphere and thus ensure a "maximum" SAD value. An exception occurs where new particle nucleation is occurring. This occurs in the lower tropical stratosphere and the middle stratosphere at the winter pole; in those cases, this methodology would not necessarily yield a robust maximum $S A D$ value.

The Method 1 maximum surface area density, $\mathrm{SAD}_{\max }$, is given by

$\mathrm{SAD}_{\text {max }}=\mathrm{SAD}_{\text {min }}^{\prime}+4\left(N_{\text {total }}-N_{\text {min }}\right) \pi r_{\text {max }}^{2}$

where $r_{\max }$ is the radius that is the solution to

$\varepsilon\left(\lambda_{\min }\right)=Q\left(r_{\max }, \lambda_{\min }\right) \pi r_{\max }^{2}\left(N_{\text {total }}-N_{\min }^{\prime}\right)$

where $\varepsilon$ is the uncertainty in the short wavelength aerosol extinction coefficient at wavelength $\lambda_{\min }$. In this case, we use a minimum $\mathrm{SAD}, \mathrm{SAD}_{\min }^{\prime}$, computed using $k(\lambda)$ instead

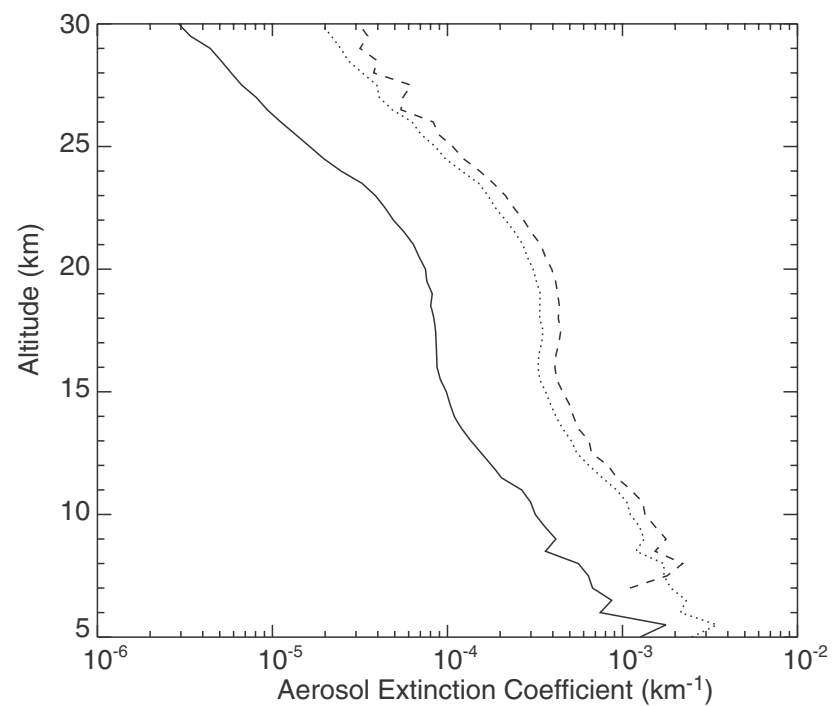

Fig. 11. Mean Northern midlatitude SAGE II aerosol extinction coefficient profiles for April 2001 for 1020 (solid), 525 (dotted), and $452 \mathrm{~nm}$ (dashed).

of $k(\lambda)-\varepsilon(\lambda)$ (with parameters $N_{\min }^{\prime}$ and $r_{\min }^{\prime}$ ) in Eqs. (3) and (4) since the resulting $\mathrm{SAD}_{\max }$ is slightly larger than using the values associated with Eq. (2). This method produces a positive though generally smaller perturbation to the $1020-\mathrm{nm}$ aerosol extinction relative to the perturbation at the shorter wavelength. This is appropriate for SAGE II data since the uncertainties at the short wavelength channels are much larger than those at $1020 \mathrm{~nm}$ and are highly correlated between channels. Unlike the minimum bound, this value is empirical and is not strictly a maximum bound to SAD and dependent on the a priori choice of $N_{\text {total }}$ though this can be perfectly justified physically.

\section{Method 2}

We have defined a more generalized form of the two monodispersed mode model which leaves the errors uncorrelated (Method 2) but leaves the total particle number, $N_{\text {total }}$, fixed at $20 \mathrm{~cm}^{-3}$. Since SAGE II aerosol errors tend to be highly correlated, this is a less realistic model than Method 1 but, as will be demonstrated below, it yields a much larger range in SAD than does Method 1. For Method 2, we compute a dense set of multi-wavelength aerosol extinction coefficient spectra that fills the bounds of three free parameters: $\mathrm{N}_{2}$ the particle number density in the large mode which lies between 0 and $20 \mathrm{~cm}^{-3}, r_{l}$ the mode radius of the large mode which lies between 0.01 and $0.5 \mu \mathrm{m}$, and $r_{s}$ the radius of the small mode which lies between 0.01 and $0.5 \mu \mathrm{m}$ (and in practice smaller than $r_{l}$ ). The maximum and minimum values for SAD occur where the computed extinction coefficients lay within the uncertainty bounds of the extinction coefficient 


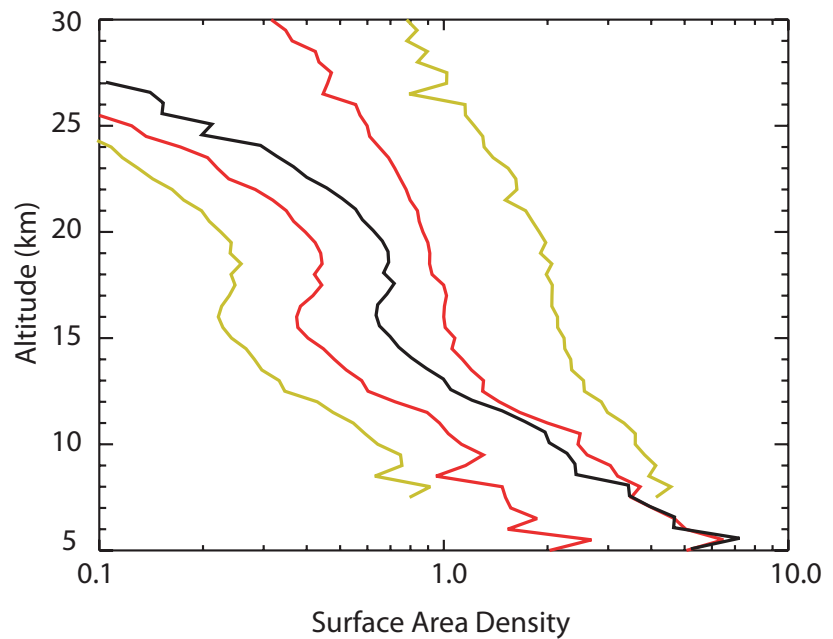

Fig. 12. This figure shows the comparison of operational SAGE II SAD (black) with the Method 1 minimum and maximum SAD using 525-nm aerosol extinction coefficient (red) and the minimum and maximum Method 2 SAD using 3 channels at 452, 525, and $1020 \mathrm{~nm}$ (gold).

measurements at two or more wavelengths $\left(\mathrm{SAD}_{\min 2}\right.$ and $\mathrm{SAD}_{\max 2}$ ). We use a look up table with more than $10^{7}$ elements to determine a solution. While this approach is laborious, it avoids the numerical instability endemic to the direct retrieval process which is exacerbated by the fine structure in the extinction kernels and the use of monodispersed size distributions. The minimum and maximum SAD values that both Method 1 and Method 2 yield are intended to be extreme and the real distribution of particle sizes is likely to be spread across a broad range of particle sizes that yield SAD values well within the bounds derived here.

\subsection{Examples of SAD bound calculations}

Figure 11 shows the mean SAGE II aerosol extinction coefficient profiles for Northern midlatitudes in April 2001. This period occurs well within the current non-volcanic period and the profiles are typical of the period between 2000 and the end of the SAGE II measurements in August 2005. Figure 12 shows a comparison of $\mathrm{SAD}_{\min }$ and $\mathrm{SAD}_{\max }$ values for Method 1 for the same period along with the operational SAD profile. In this case, we show results for $N_{\text {total }}$ equal to $20 \mathrm{~cm}^{-3}$ and using extinction at $525 \mathrm{~nm}$ as the short wavelength aerosol channel. We found that the SAD bounds are not strongly influenced by the choice of the 452 or $525 \mathrm{~nm}$ channels and we limit discussion to the use of the $525-\mathrm{nm}$ channel. We also find for these parameters that the difference between the minimum and maximum values of SAD increases from about a factor of 2 at $10 \mathrm{~km}$ to about a factor of 4 at $25 \mathrm{~km}$ and roughly follows the increase in the 525 to 1020-nm extinction coefficient ratio (decreasing mean particle size). The operational model tends to lie within these
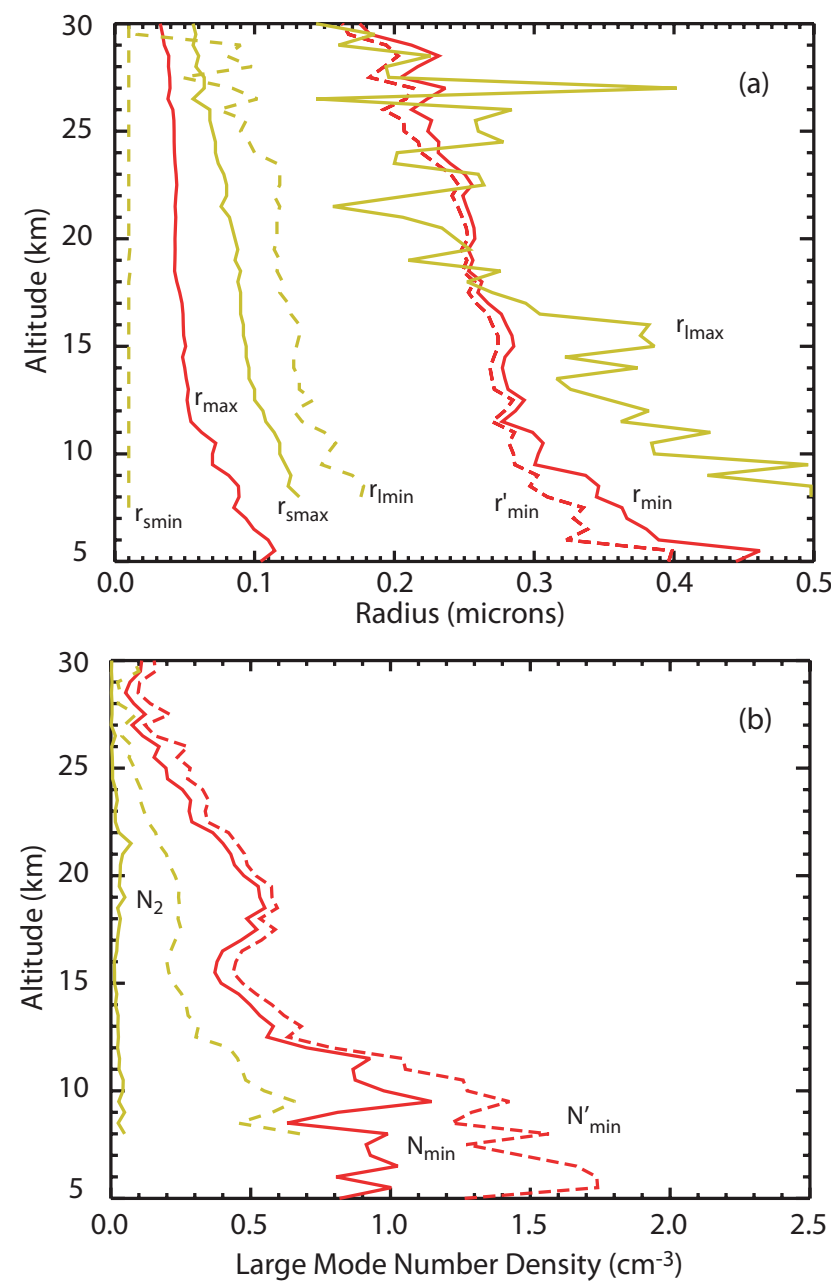

Fig. 13. This figure shows the profiles of the Method 1 dependent parameters $r_{\min }, r_{\max }$, and $r_{\min }^{\prime}$ (on frame (a)) and $N_{\min }$ and $N_{\min }^{\prime}$ (b) in red. In addition, it shows Method 2 free parameters $r_{\text {lmax }}, r_{\text {lmin }}, r_{\mathrm{smax}}$, and $r_{\mathrm{smin}}$ (a) and $\mathrm{N}_{2}$ for the maximum SAD (solid) and for the minimum SAD (dashed) in gold.

bounds where it runs from a little less than $\mathrm{SAD}_{\max }$ at $10 \mathrm{~km}$ to a little greater than $\mathrm{SAD}_{\min }$ at $25 \mathrm{~km}$. In the main aerosol region below $25 \mathrm{~km}$, the operational value lies around $30 \%$ of the way from $\mathrm{SAD}_{\min }$ to $\mathrm{SAD}_{\max }$ and thus follows the general expectation that it would tend to produce surface area density values that are on the low end of the range of possible values.

Figure 12 also shows the minimum and maximum SAD values for the 3-channel results from Method 2. The 2 and 3channel versions (using 525 and $1020 \mathrm{~nm}$ and 452, 525, and $1020 \mathrm{~nm}$ channels respectively) yield very similar results so we restrict discussion to the three channel method. Here, we find that the range in SAD is much larger than found for Method 1 and runs from a factor of 6 near $10 \mathrm{~km}$ to a factor of $\sim 15$ at $25 \mathrm{~km}$. The larger domain is an outcome of the solutions Method 2 preferentially produces for the minimum 
and maximum SADs. The minimum solution uniformly occurs for the shallowest allowed slope in the extinction coefficient wavelength dependence (the largest allowed negative departures at the short wavelengths and largest allowed positive departures at $1020 \mathrm{~nm}$ ) whereas the maximum SAD solution invariably occurs for the steepest allowed solution (the largest allowed positive departures at the short wavelengths and largest allowed negative departures at $1020 \mathrm{~nm}$ ). This result is not surprising since the steeper slope implies smaller particles which require greater surface area to produce an equivalent extinction as larger particles. The effect of the slope change is extremely non-linear (as implied by Eq. (1)) and overwhelms any change in SAD implied by the relatively minor changes in the absolute magnitude of the extinction coefficients.

Figure 13 shows the derived free parameters $\left(r_{\min }, r_{\max }, r_{\min }^{\prime}, N_{\min }\right.$, and $\left.N_{\min }^{\prime}\right)$ for these solutions. We find that $r_{\min }$ for the minimum and maximum SADs for Method 1 are essentially the same and the small particle size for the maximum SAD lies between 30 and $50 \mathrm{~nm}$ for most of the stratosphere. The large mode, $r_{\text {Imax }}$, for the maximum SAD in Method 2 is close to $r_{\min }$ from Method 1 particularly above $15 \mathrm{~km}$. On the other hand the small mode particle radius, $r_{\mathrm{smax}}$, is larger than $r_{\max }$ from Method 1 and varies from 60 to $100 \mathrm{~nm}$ in the stratosphere. For the minimum SAD for Method 2, $r_{\mathrm{smax}}$ does not contribute significantly to the total surface area density but uniformly selects the smallest allowed particle size. As a result, the Method 2 approach effectively selects a single mode solution for minimum SAD and follows the argument made for the definition of the Method 1 minimum SAD. For both methods, the number density of the large mode for both the minimum and maximum SAD is less than $1 \mathrm{~cm}^{-3}$ above $10 \mathrm{~km}$ and generally decreases with altitude. This result is consistent with past efforts to fit SAGE II extinctions with a priori size distribution models like the log-normal. In these efforts, the size distributions were commonly very narrow and the derived number densities were often much smaller than $\sim 10 \mathrm{~cm}^{-3}$ measured by in situ instruments (e.g., Wang et al., 1989).

Obviously, the dependence of the maximum SAD model on a priori parameters plays a role in understanding the upper limit of SAD that can be computed from SAGE II extinction coefficient measurements. For instance, doubling $N_{\text {total }}$ to $40 \mathrm{~cm}^{-3}$ yields a 15 to $40 \%$ increase in both $\mathrm{SAD}_{\max }$ and $\mathrm{SAD}_{\text {min }}$ for Method 1 depending on altitude. The dependence is not linear since the increase in number density is in part compensated for by a reduction in the inferred particle size for the small mode aerosol. We find that including a third monodispersed mode never yields a significant third mode for either the minimum or maximum SAD. These results make us confident that two monodispersed modes are yielding the extreme results that we are seeking.

As an extension to this study, we have examined the impact of additional measurements on the range of surface area

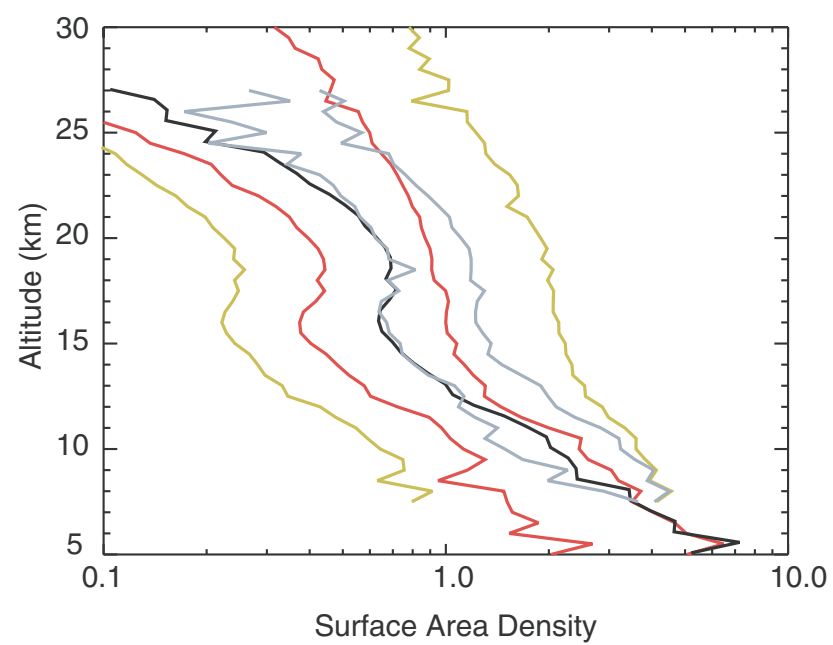

Fig. 14. This figure shows the comparison of operational SAGE II SAD (black) with the Method 1 SAD using 525-nm aerosol extinction coefficient (red) and the Method 2 SAD using the 525 and $1020 \mathrm{~nm}$ channels (gold) and the Method 2 SAD computed using the channels at 525 and $1020 \mathrm{~nm}$ plus a pseudo-infrared channel (grey).

density possible from SAGE II measurements. In particular, we consider including a channel from the infrared where sulfate aerosol strongly absorbs. In the infrared, provided that the refractive index of the aerosol is well known, the aerosol extinction coefficient is roughly proportional to aerosol volume density for a broad range of aerosol sizes and as a result insensitive to aerosol size. We have examined this effect using the SAGE II operational estimate of aerosol volume with an uncertainty of $15 \%$ as a stand-in for an infrared measurement for use along with the 3 visible channel version of Method 2. We find that, as shown in Fig. 14, the range of SAD is reduced to a factor of at least 4 throughout the profile relative to the nominal Method 2 results and now lies between 1.5 and 2. Since we are using a SAGE II-based aerosol volume estimate as stand-in for an infrared channel, the range of SAD values should be interpreted cautiously. Nonetheless, we conclude that a mix of visible and infrared aerosol measurements would be a much stronger measurement ensemble than either visible or infrared measurements alone.

\subsection{Summary of aerosol surface area density study}

The SAD inferred from SAGE II visible and near-infrared aerosol extinction coefficient measurements is mathematically unbounded; however, modest physically-based restrictions to the underlying particle number density reduces the range of SAD values for background periods to a factor of 2 to 15 depending on altitude and assumptions regarding the nature of the measurement uncertainty. It is important to remember that this range is the outcome of several unrealistic 
assumptions about the nature of the aerosol and the SAGE II measurements. However, this study helps to put a broad bracket around the range of SAD values that can be produced from SAGE II extinction coefficient measurements. Method 1 is the most realistic in its treatment of the SAGE II measurements and measurement errors (forcing errors between channels to be correlated) whereas Method 2 allows them to be completely uncorrelated. As a result, we believe that the maximum range of reasonable $\mathrm{SAD}$ values around the current operational values is on the order of a factor of 2 for non-volcanic conditions. This factor is comparable to or greater than the differences found between the operational SAGE II SAD and SAD measurements made by in situ measurements such as the University of Wyoming Optical Particle Counter (e.g., Thomason and Peter, 2006; Hervig et al., 2002). The SAD model described above may not provide reasonable limits in regions of the stratosphere where strong particle nucleation occurs such as the lower tropical stratosphere (Brock et al., 1995) or the polar winter middle stratosphere (Deshler et al., 2003) since number densities may be considerably larger than those considered here though the SAGE II-measured extinctions remain valid.

Acknowledgements. We are grateful for the support by SPARC/WCRP and for many helpful discussions with the Lead Authors of SPARC's Assessment of Stratospheric Aerosol Properties (ASAP). We also thank the reviewers for their insightful comments and efforts toward improving this manuscript.

Edited by: W. Ward

\section{References}

Anderson, S. M. and Mauersberger, K.: Laser measurements of ozone absorption cross sections in the Chappuis band, Geophys. Res. Lett., 19, 933-936, 1992.

Anderson, S. M., Morton, J., and Mauersberger, K.: Near-infrared absorption spectra of $16 \mathrm{O} 3$ and 1803: Adiabatic energy of the 1A2 state, J. Chem. Phys., 93, 3826-3832, 1990.

Anderson, S. M., Maeder, J., and Mauersberger, K.: Effect of isotopic substitution on the visible absorption spectrum of ozone, J. Chem. Phys., 94, 6351-6357, 1991.

Anderson, S. M., Hupalo, P., and Mauersberger, K.: Rotational structure in the near-infrared absorption spectrum of ozone, J. Chem. Phys., 99, 737-739, 1993a.

Anderson, S. M., Hupalo, P., and Mauersberger, K.: Ozone absorption cross section measurements in the Wulf bands, Geophys. Res. Lett., 20, 1579-1582, 1993b.

Bingen, C., Fussen, D., and Vanhellemont, F.: A global climatology of stratospheric aerosol size distribution parameters derived from SAGE II data over the period 1984-2000: 2. Reference data, J. Geophys. Res., 109, D06202, doi:10.1029/2003JD003511, 2004b.

Borchi, F. and Pommereau, J.-P.: Evaluation of ozonesondes, HALOE, SAGE II and III, Odin-OSIRIS and -SMR, and ENVISAT-GOMOS, -SCIAMACHY and -MIPAS ozone profiles in the tropics from SAOZ long duration balloon measurements in 2003 and 2004, Atmos. Chem. Phys., 7, 2671-2690, 2007, http://www.atmos-chem-phys.net/7/2671/2007/.
Brock, C. A., Hamill, P., Wilson, J. C., Jonsson, H. H., and Chan, K. R.: Particle formation in the upper tropical troposphere: A source of nuclei for the stratospheric aerosol, Science, 270, 1650-1653, 1995.

Burkholder, J. B. and Talukdar, R. K.: Temperature dependence of the ozone absorption spectrum over the wavelength range 410 to 760 nm, Geophys. Res. Lett., 21, 581-584, 1994.

Deshler, T., Hervig, M. E., Hofmann, D. J., Rosen, J. M., and Liley, J. B.: Thirty years of in situ stratospheric aerosol size distribution measurements from Laramie, Wyoming $\left(41^{\circ} \mathrm{N}\right)$ using balloon-borne instruments, J. Geophys. Res., 108, 4167, doi:10.1029/2002JD002514, 2003.

Hervig, M. E. and Deshler, T.: Evaluation of aerosol measurements from SAGE II, HALOE, and balloonborne optical particle counters, J. Geophys. Res., 107(D3), 4031, doi:10.1029/2001JD000703, 2002.

Hervig, M. E., Deshler, T., and Russell III, J. M.: Aerosol size distributions obtained from HALOE spectral extinction measurements, J. Geophys. Res., 103, 1573-1583, 1998.

Hofmann, D. J. and Rosen, J. M.: Antarctic observations of stratospheric aerosol and high altitude condensation nuclei following the El Chichon eruption, Geophys. Res. Lett., 12, 13-16, 1985.

McCormick, M. P., Thomason, L. W., and Trepte, C. R.: Atmospheric effects of the Mount Pinatubo eruption, Nature, 373, 399-404, 1995.

Pitts, M. C. and Thomason, L. W.: The impact of the eruptions of Mount Pinatubo and Cerro Hudson on Antarctic aerosol levels during the 1991 austral spring, Geophys. Res. Lett., 20, 24512454, 1993.

Randel, W., Udelhofen, P., Fleming, E., Geller, M., Gelman, M., Hamilton, K., Karoly, D., Ortland, D., Pawson, S., Swinbank, R., Wu, F., Baldwin, M., Chanin, M.-L., Keckhut, P., Labitzke, K., Remsberg, E., Simmons, A., and Wu, D.: The SPARC Intercomparison of Middle-Atmosphere Climatologies, J. Climate, 17, 986-1003, 2004.

Russell, P. B., Livingston, J. M., Pueschel, R. F., Hughes, J. J., Pollack, J. B., Brooks, S. L., Hamill, P., Thomason, L. W., Stowe, L. L., Deshler, T., Dutton, E. G., and Berstrom, R. W.: Global to microscale evolution of the Pinatubo volcanic aerosol, derived from diverse measurements and analyses, J. Geophys. Res., 101, 18 745-18 764, 1996.

Shettle, E. P. and Anderson, S. M.: New Visible and Near IR Ozone Cross Sections for MODTRAN, presented at the 17th Annual Review Conference on Atmospheric Transmission Models, Phillips Laboratory, Bedford, MA, 7-8 June, 1994.

Steele, H. M. and Hamill, P.: Effects of temperature and humidity on the growth and optical properties of sulfuric acid-water droplets in the stratosphere, J. Aerosol Sci., 12, 517-528, 1981.

Steele, H. M. and Turco, R. P.: Retrieval of aerosol size distributions from satellite extinction spectra using constrained linear inversion, J. Geophys. Res., 102, 16 737-16 747, 1997.

Thomason, L. W., Kent, G. S., Trepte, C. R., and Poole, L. R.: A comparison of the stratospheric aerosol background periods of 1979 and 1989-1991, J. Geophys. Res., 102, 3611-3616, 1997a.

Thomason, L. W., Poole, L. R., and Deshler, T. R.: A global climatology of stratospheric aerosol surface area density as deduced from SAGE II: 1984-1994, J. Geophys. Res., 102, 8967-8976, 1997b. 
Thomason, L. W. and T. Peter (Eds.): Assessment of Stratospheric Aerosol Properties (ASAP), SPARC Report No. 4, WCRP124, WMO/TD-No. 1295, http://www.atmosp.physics.utoronto. ca/SPARC/index.html, February, 2006.

Trepte, C. R., Thomason, L. W., and Kent, G. S.: Banded structures in stratospheric aerosol distributions, Geophys. Res. Lett., 22, 2397-2400, 1994.

Wang, P. H., McCormick, M. P., McMaster, L. R., Chu, W. P., Swissler, T. J., Osborn, M. T., Russell, P. B., Oberbeck, V. R., Livingston, J., Rosen, J. M., Hofmann, D. J., Grams, G. W., Fuller, W. H., and Yue, G. K.: SAGE II aerosol data validation based on retrieved aerosol model size distribution from SAGE II aerosol measurements, J. Geophys. Res., 94, 8381-8393, 1989.
Wang, H. J., Cunnold, D. M., Thomason, L. W., Zawodny, J. M., and Bodeker, G. E.: Assessment of SAGE version 6.1 ozone data quality, J. Geophys. Res., 107(D23), 4691, doi:10.1029/2002JD002418, 2002.

Yue, G. K.: A new approach to retrieval of aerosol size distributions and integral properties from SAGE II aerosol extinction spectra, J. Geophys. Res., 104, 27 491-27 506, 1999. 